\title{
Optical Coherence Tomography Patterns in Diabetic Macular Edema and Its Impact on Anatomical and Functional Outcome after Intravitreal Injection of Ranibizumab
}

\author{
Ahmed T. Al Sayed", Hassan A. Ali, Mostafa M. Mostafa and Abdelaleem A. Elgendy \\ Department of ophthalmology and clinical pathology, Faculty of Medicine, Al-Azhar University, Cairo, Egypt \\ *Corresponding author: Ahmed T. Al Sayed, E-mail: Tefa2end@ @otmail.com, Telephone No.: +2001005027451
}

\begin{abstract}
Background: to report the anatomical and functional outcome based on patterns of optical coherence tomography (OCT) morphology in diabetic macular edema (DME), following treatment with intravitreal ranibizumab (IVR) injection.

Aim of the Work: to evaluate the role of OCT in detecting the patterns of DME and its effect on anatomical and functional outcome after IVR injection.

Patients and Methods: this study enrolled 30 eyes of patients with DME. These patients were categorized into 3 groups according to OCT finding, group I- 10 eyes with diffuse retinal thickening (DRT), group II- 10 eyes with cystoid macular edema (CME), group III- 10 eyes with neurosensory detachment (NSD). All patients received a three monthly doses of intravitreal ranibizumab. Best-corrected visual acuity (BCVA) and central macular thickness (CMT) were assessed before and after the treatment (in the $1^{\text {st }}, 3^{\text {rd }}$ and $6^{\text {th }}$ month).

Results: at month 6, mean BCVA changed with $0.24 \pm 0.057$ Decimal $(\mathrm{P}<0.001), 0.23 \pm 0.10$ Decimal $(\mathrm{P}<0.001)$ and $0.11 \pm 0.12$ Decimal $(\mathrm{P}=0.019)$, respectively, for DRT, CME and NSD groups. Mean CMT decreased by $119.80 \pm$ $84.58 \mu \mathrm{m}(\mathrm{P}=0.002)$ in DRT group, by83.00 $\pm 65.98 \mu \mathrm{m}(\mathrm{P}=0.003)$ in CME group and by $102.30 \pm 110.25 \mu \mathrm{m}$ $(\mathrm{P}=0.017)$ in NSD group. The DRT group was associated with superior BCVA improvement and greater reduction in CMT.

Conclusion: we found statistically significant improvement of BCVA and CMT in all groups of DME based on OCT pattern at final follow-up with greater reduction in CMT and superior BCVA improvement in DRT group.

Keywords: optical coherence tomography, diabetic macular edema, intravitreal injection, ranibizumab.
\end{abstract}

\section{INTRODUCTION}

Diabetic macular edema (DME) is a leading cause of visual impairment in the diabetic population ${ }^{(\mathbf{1})}$. Vascular endothelial growth factor (VEGF) is a potent endothelial cell angiogenic factor, and a powerful mediator of vascular permeability. It leads to a breakdown of the blood-retinal barrier in DR, causing leakage of intravascular fluid from abnormal retinal capillaries, which result in $\mathrm{DME}^{(2)}$.

The application of VEGF inhibitors is a therapy with proven effect which is widely used because it is tolerated well and because of its low risk of systemic and eye complications $^{(3)}$.

So,VEGF is a key factor in pathogenesis of DME, but it is not the only one and inhibition of it alone is not sufficient for its effective treatment. Additional studies are necessary to resolve some important matters such as optimum dosage, duration of treatment, safety, and dependence on optical coherence tomography (OCT) patterns of edema ${ }^{(4)}$.OCT provides detailed information about retinal microstructure and measures retinal thickness with high precision and reproducibility ${ }^{(5)}$. The spectral-domain OCT (SD-OCT) machines have numerous improvements that enhance our ability to examine retinal microstructure and obtain more reliable measurements.

OCT morphology patterns in DME may predict the effect of intravitreal injection of anti.VEGF as a tool in management of $\mathrm{DME}^{(\mathbf{6})}$.

\section{AIM OF THE WORK}

The purpose of this study is to evaluate the role of optical coherence tomography (OCT) in detecting the patterns of diabetic macular edema (DME) and its effect on anatomical and functional outcome after intravitreal ranibizumab (IVR) injection.

\section{PATIENTS AND METHODS}

A study of 30 eyes of patients with DME was conducted in Al-SayedGalal and Al MashreqEye Hospital with three times injection one month apart.

The study was approved by the Ethics Board of Al Azhar University. An informed written consent was taken from each participant in the study.

The patients with DME were categorized into3 groups according to OCT findings:

Group I- 10 eyes with diffuse retinal thickening (DRT).

Group II- 10 eyes with cystoid macular edema (CME).

Group III- 10 eyes with neurosensory detachment (NSD).

All patients were received a three-monthly doses $(0.5 \mathrm{mg})$ of intravitreal ranibizumab (lucentis) (Novartis Pharmaceuticals). An ophthalmological 
examination was conducted before and after treatment at month 1,3 ,and

Examination included:

1. Best corrected visual acuity (BCVA)

2. Evaluation of anterior segment.

3. Measuring intraocular pressure using applanation tonometer.

4. Fundus examination with indirect ophthalmoscopy and slit lamp biomicroscopy.

5. OCT with measurementof the central macular thickness (CMT).

Inclusion criteria: Patient with diabetic macular edema with central macular thickness over $250 \mu \mathrm{m}$.

Exclusion criteria:

- Previous intraocular surgical intervention or intravitreal injection within 6 months.

- Previous laser photocoagulation within 6 months.

- Macular edema with a different etiology as other retinal diseases, glaucoma and inflammatory diseases.

- Vitreomacular traction.

\section{STATISTICAL ANALYSIS}

Outcome measures were a change in mean BCVA and CMT in each group during the six month follow-up period. Statistical analysis, $t$-test for parametric data, and one way ANOVA was performed with SPSS statistical software (version 17.0.1, IBM Corp., Somers, NY, USA). $P<0.05$ was considered statistically significant.

\section{RESULTS}

Table (1): Comparison between groups according to demographic data.

\begin{tabular}{|l|l|l|l|l|}
\hline & DRT & CME & NSD & $\begin{array}{l}\text { P among } \\
\text { groups }\end{array}$ \\
\hline $\begin{array}{l}\text { Mean age } \\
\text { (years) } \pm \text { SD }\end{array}$ & $\begin{array}{l}54.80 \pm \\
8.52\end{array}$ & $\begin{array}{l}54.60 \pm \\
15.41\end{array}$ & $\begin{array}{l}54.00 \pm \\
8.87\end{array}$ & 0.987 \\
\hline $\begin{array}{l}\text { Female/male } \\
\text { (No. of eyes) }\end{array}$ & $5 / 5$ & $4 / 6$ & $6 / 4$ & 0.670 \\
\hline $\begin{array}{l}\text { Type of diabetes } \\
\text { (I/ II) (No. of eyes) }\end{array}$ & $4 / 6$ & $3 / 7$ & $4 / 6$ & 0.866 \\
\hline $\begin{array}{l}\text { Patients who } \\
\text { received insulin } \\
\text { treatment } \\
\text { (No. of eyes ) \% }\end{array}$ & 10 & 7 & 7 & 0.153 \\
\hline $\begin{array}{l}\text { SD: Standard Deviation; } \\
\text { DRT: Diffuse Retinal Thickening; } \\
\text { CME: Cystoid Macular Edema; } \\
\text { NSD: Neurosensory Detachment }\end{array}$ & $(70 \%)$ & $(70 \%)$ & \\
\hline
\end{tabular}

This table (1) shows no statistically significant difference between groups according to demographic data.

Table (2): Mean BCVA and CMT of each group before treatment and after month 1, 3 and 6 of treatment

\begin{tabular}{|c|c|c|c|c|c|}
\hline & & DRT & CME & NSD & $\begin{array}{l}\text { P among } \\
\text { groups }\end{array}$ \\
\hline 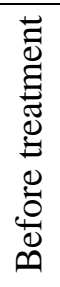 & $\begin{array}{l}\text { BCVA } \\
\text { (decimal } \\
\pm \mathrm{SD}) \\
\mathrm{CMT} \\
(\mu \mathrm{m} \pm \\
\mathrm{SD})\end{array}$ & $\begin{array}{l}0.33 \pm \\
0.21 \\
409.50 \pm \\
108.015\end{array}$ & $\begin{array}{l}0.51 \pm \\
0.19 \\
\\
369.70 \pm \\
74.337\end{array}$ & $\begin{array}{l}0.33 \pm \\
0.21 \\
408.90 \\
\pm \\
113.572\end{array}$ & 0.091 \\
\hline 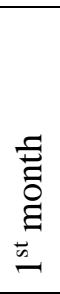 & $\begin{array}{l}\text { BCVA } \\
\text { (decimal } \\
\pm \mathrm{SD}) \\
\mathrm{CMT} \\
(\mu \mathrm{m} \pm \\
\mathrm{SD})\end{array}$ & $\begin{array}{l}0.48 \pm \\
0.24 \\
309.6 \pm \\
64.90\end{array}$ & $\begin{array}{l}0.64 \pm \\
0.20 \\
\\
317.20 \\
\pm 53.14\end{array}$ & $\begin{array}{l}0.50 \\
\pm 0.19 \\
278.60 \\
\pm 71.91\end{array}$ & 0.566 \\
\hline 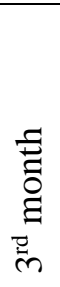 & $\begin{array}{l}\begin{array}{l}\text { BCVA } \\
\text { (decimal }\end{array} \\
\pm \mathrm{SD}) \\
\mathrm{CMT} \\
(\mu \mathrm{m} \pm \\
\mathrm{SD})\end{array}$ & $\begin{array}{l}0.47 \pm \\
0.23 \\
\\
302.80 \\
\pm 64.98\end{array}$ & $\begin{array}{l}0.72 \pm \\
0.23 \\
285.10 \pm \\
34.34\end{array}$ & $\begin{array}{l}0.44 \pm \\
0.29 \\
\\
269.10 \\
\pm 74.54\end{array}$ & 0.469 \\
\hline 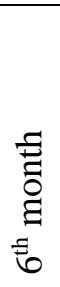 & $\begin{array}{l}\begin{array}{l}\text { BCVA } \\
\text { (decimal }\end{array} \\
\pm \mathrm{SD}) \\
\mathrm{CMT} \\
(\mu \mathrm{m} \pm \\
\mathrm{SD})\end{array}$ & $\begin{array}{l}0.57 \pm \\
0.21 \\
\\
289.70 \\
\pm 61.54\end{array}$ & $\begin{array}{l}0.74 \pm \\
0.22 \\
\\
286.70 \\
\pm 34.64\end{array}$ & $\begin{array}{l}0.44 \pm \\
0.29 \\
\\
306.60 \\
\pm 74.39\end{array}$ & 0.031 \\
\hline \multicolumn{6}{|c|}{$\begin{array}{l}\text { BCVA: Best Corrected Visual Acuity; CMT: Central } \\
\text { Macular Thickness; SD: Standard Deviation; DRT: } \\
\text { Diffuse Retinal Thickening; CME: Cystoid Macular } \\
\text { Edema; NSD: Neurosensory Detachment. }\end{array}$} \\
\hline
\end{tabular}

This table (2) shows statistically significant difference between groups according to BCVA at month 3 and 6 after treatment.

Table (3): Comparison between groups according to mean change of BCVA and CMT before injection and at 1 month

\begin{tabular}{|c|c|c|c|}
\hline & DRT & CME & NSD \\
\hline \multicolumn{3}{|c|}{ BCVA change (0-1 month) } & \\
\hline$($ decimal $\pm \mathrm{SD})$ & $\begin{array}{c}0.15 \pm \\
0.74\end{array}$ & $\begin{array}{c}0.13 \pm \\
0.12\end{array}$ & $\begin{array}{c}0.17 \pm \\
0.08\end{array}$ \\
\hline $\mathrm{P}$ within group & $<0.001$ & 0.006 & $<0.001$ \\
\hline \multicolumn{4}{|c|}{ CMT change (0-1 month) } \\
\hline$(\mu \mathrm{m} \pm \mathrm{SD})$ & $\begin{array}{l}99.90 \pm \\
79.41\end{array}$ & $\begin{array}{l}52.50 \pm \\
50.55\end{array}$ & $\begin{array}{l}121.30 \pm \\
96.85\end{array}$ \\
\hline P within group & 0.003 & 0.009 & 0.003 \\
\hline
\end{tabular}


Statistically there was a significant improvement in each group in BCVA and CMT at month 1 after treatment with greater reduction in CMT and superior BCVA improvement in NSD group (Table 3).

Table (4): Comparison between groups according to mean change of BCVA and CMT before injection and at month 3 .

\begin{tabular}{|l|l|l|l|}
\hline & DRT & CME & NSD \\
\hline $\begin{array}{l}\text { BCVA change } \\
(0-3 \text { month })\end{array}$ & $0.14 \pm$ & $0.21 \pm$ & $0.19 \pm$ \\
(decimal \pm & 0.14 & 0.99 & 0.10 \\
SD) & 0.012 & $<0.001$ & $<0.001$ \\
P within group & & & \\
\hline $\begin{array}{l}\text { CMT change } \\
(0-3 \text { month })\end{array}$ & $106.70 \pm$ & $84.60 \pm$ & $139.80 \pm$ \\
$(\mu \mathrm{m} \pm$ SD) & 78.42 & 80.03 & 119.07 \\
P within group & 0.002 & 0.009 & 0.005 \\
\hline
\end{tabular}

Statistically there was a significant improvement in each group in BCVA and CMT at month 3 after treatment with greater reduction in CMT in NSD group and superior BCVA improvement in CME group (Table 4).

Table (5): Comparison between groups according to mean change of BCVA and CMT before injection and at month 6 .

\begin{tabular}{|c|c|c|c|}
\hline & DRT & CME & NSD \\
\hline $\begin{array}{l}\text { BCVA change } \\
\frac{(0-6 \text { month })}{(\text { decimal } \pm S D)} \\
P \text { within group }\end{array}$ & $\begin{array}{ll}0.24 & \pm \\
0.057 & \\
<0.001 & \end{array}$ & $\begin{array}{l}0.23 \pm \\
0.10 \\
<0.001\end{array}$ & $\begin{array}{l}0.11 \\
0.12 \\
0.019\end{array}$ \\
\hline $\begin{array}{l}\frac{\text { CMT change }}{(0-6 m o n t h)} \\
\frac{(\mu \mathrm{m} \pm \mathrm{SD})}{\mathrm{P} \text { within group }}\end{array}$ & $\begin{array}{l}119.80 \quad \pm \\
84.58 \\
0.002\end{array}$ & $\begin{array}{l}83.00 \\
\pm \\
65.98 \\
0.003\end{array}$ & $\begin{array}{l}102.30 \quad \pm \\
110.25 \\
0.017\end{array}$ \\
\hline
\end{tabular}
improvement in each group in BCVA and CMT at month 6 after treatment with greater reduction in CMT and superior BCVA improvement in DRT group (Table 5).

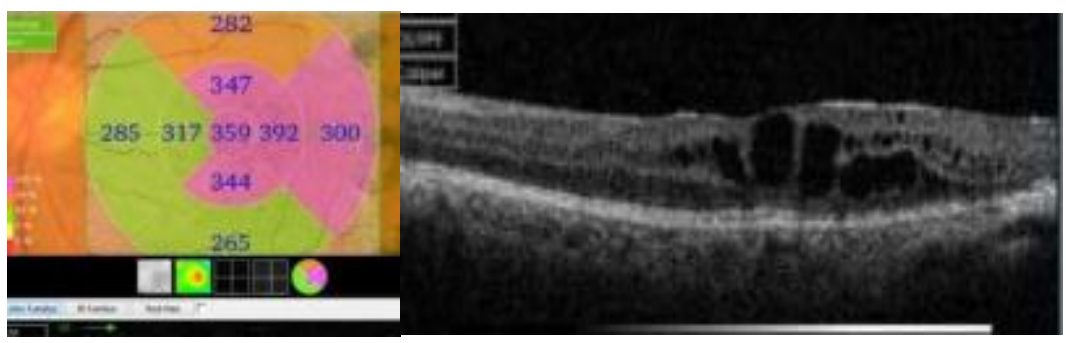

Figure (1): case No 1.

OCT evaluation before injection of IVR of left eye of 50 years old female with history of diabetes since 20 years and had DRT. BCVA was 0.5 (decimal) and CMT was $359 \mu \mathrm{m}$.

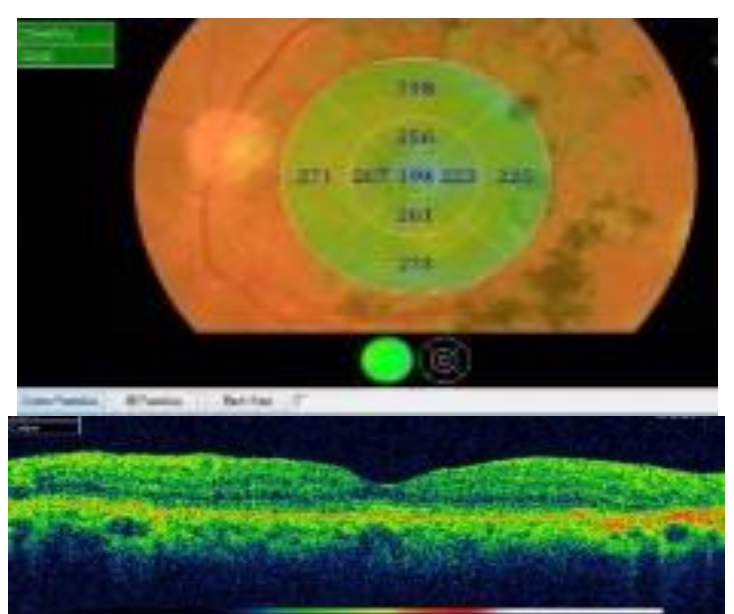

Figure (2): case No 1. OCT evaluation after 6 months of injection of IVR of left eye of 50 year old female with history of diabetes since 20 years and had DRT. BCVA was 0.8 (decimal) and CMT was $194 \mu \mathrm{m}$
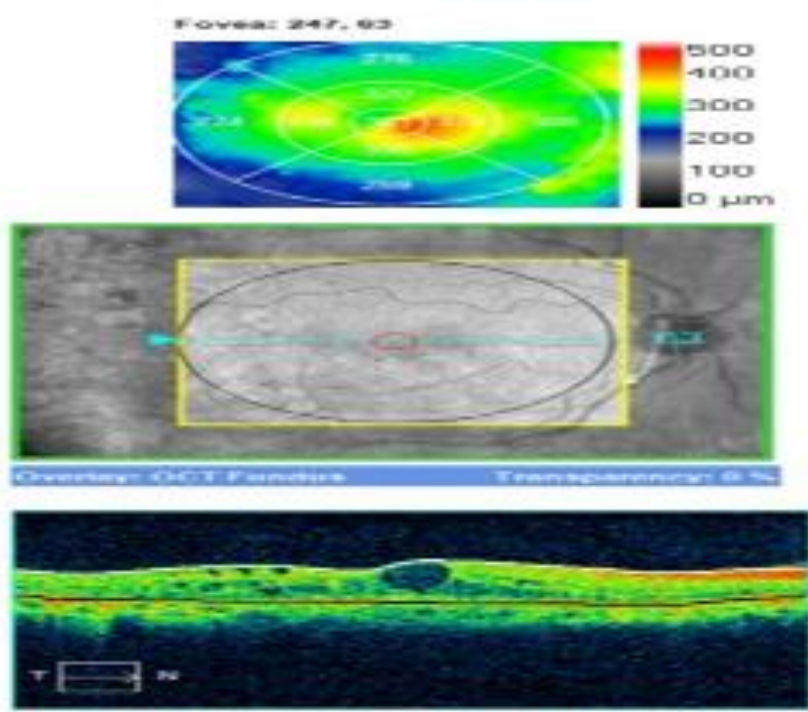

Figure (3): case No 2. OCT evaluation before injection of IVR of right eye of 60 years old female who was diabetic since 10 years and had CME. BCVA was 0.5 (decimal) and CMT was $361 \mu \mathrm{m}$. 


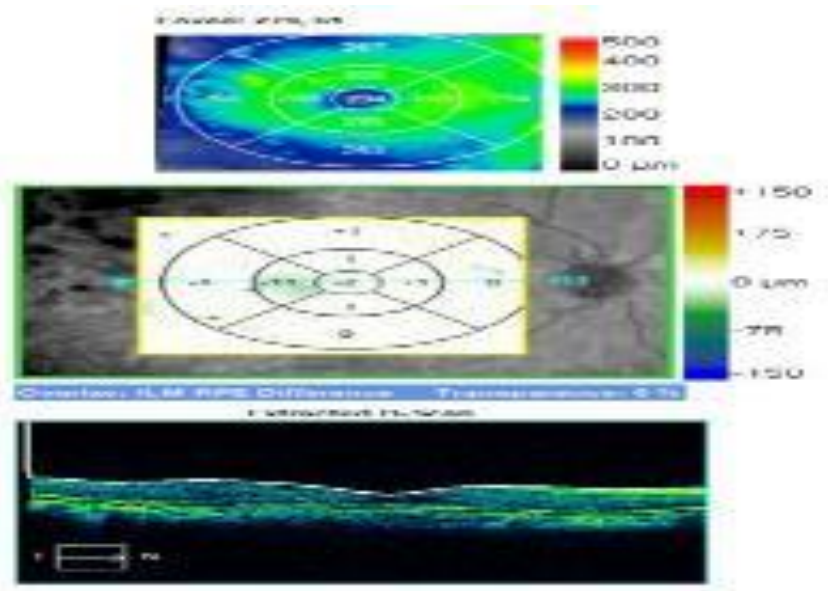

Figure (4): case No 2.

OCT evaluation after 6 month of injection of IVR of right eye of 60 year old female who was diabetic since 10 years and had CME. BCVA was 0.8 (decimal) and CMT was $234 \mu \mathrm{m}$.

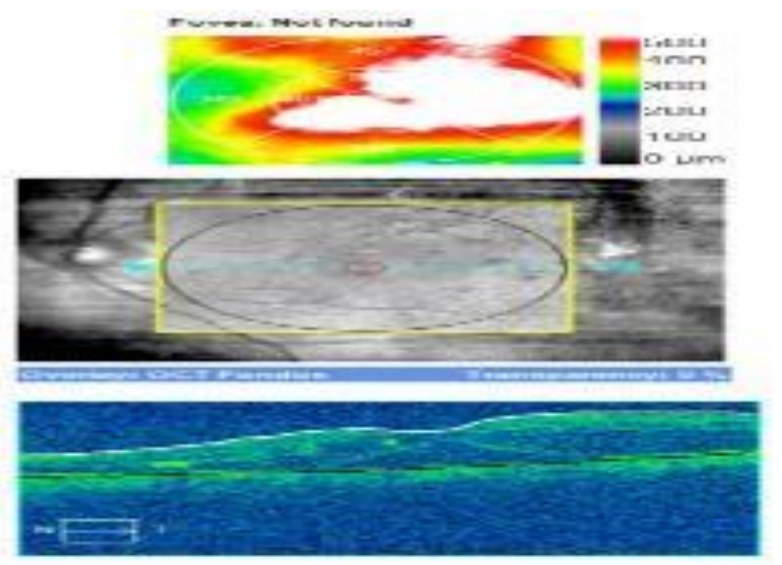

Figure (5): case No 3.

OCT evaluation before injection of IVR of left eye of 56 year old male with history of diabetes since 21 years and had NSD. BCVA was 0.3 (decimal) and CMT was 550 $\mu \mathrm{m}$.

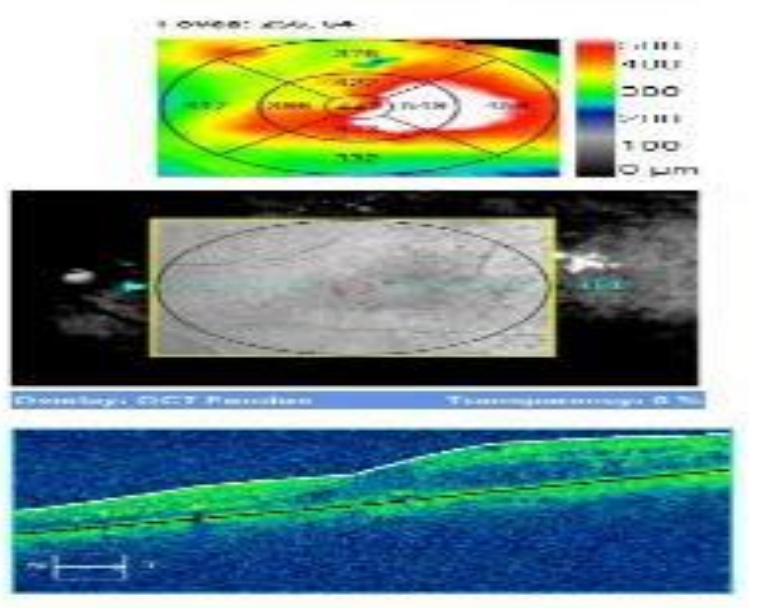

Figure (6): case No 3. OCT evaluation after 6 month of injection of IVR of left eye of 56 year old male with history of diabetes since 21 years and had NSD. BCVA was 0.4 (decimal) and CMT was $447 \mu \mathrm{m}$.

\section{DISCUSSION}

DME is a major cause of vision loss in patients with diabetic retinopathy ${ }^{(7)}$.It results from the disruption of blood retinal barrier, causing leakage of intravascular fluid from abnormal retinal capillaries, which result in DME. In recent years optical coherent tomography has become the most used diagnostic tool for DME. The use of technology such as OCT, offers the opportunity to assess the macula in histologic cross sections, and make objective and quantitative evaluations of $\mathrm{DME}^{(\mathbf{8})}$. There are several classifications of DME according to the OCT criteria $^{(9)}$. This particular study uses the classification of Otani, according to which nontractional DME is three types: DRT, CME and $\mathrm{NSD}^{(\mathbf{1 0})}$. Vascular endothelial growth factor (VEGF)-A has been identified as a key vascular permeability factor that leads to neovascularization and blood retinal barrier (BRB) disruption, making it an attractive target for pharmaceutical intervention ${ }^{(\mathbf{1 1})}$.

Our study found that all DME groups was associated with improvement of BCVA and CMT following intravitreal ranibizumab(IVR) at month 1,3, and 6. Our study found a correlation between mean BCVA, mean CMT and OCT patterns of DME. The DRT type has better BCVA and lower CMT than other types of DME. We found a correlation between reduction of CMT and BCVA improvement.

At final follow-up, we found statistically significant improvement in each group in BCVA and $\mathrm{CMT}$ at month 6 after treatment with greater reduction in CMT and superior BCVA improvement in DRT group where mean BCVA increased by $(0.24 \pm 0.057$ Decimal $)$ $(\mathrm{P}<0.001)$ and mean CMT decreased by $(119.80 \pm$ $84.58 \mu \mathrm{m})(\mathrm{P}=0.002)$. In $\mathrm{CME}$ group mean $\mathrm{BCVA}$ increased by $(0.23 \pm 0.10$ Decimal $)(P<0.001)$ and mean CMT decreased by $(83.00 \pm 65.98 \mu \mathrm{m})(\mathrm{P}=0.003)$. In NSD group mean BCVA increased by $(0.11 \pm 0.12$ Decimal) $(\mathrm{P}=0.019)$ and mean CMT decreased by $(102.30 \pm 110.25 \mu \mathrm{m})(\mathrm{P}=0.017)$.

Previous studies demonstrated the effectiveness of intravitreal anti-VEGF treatment of the various OCT types of DME. Kim et al. ${ }^{(12)}$,found that intravitreal injection of bevacizumab was more effective in the diffuse retinal thickening than in the focal cystoid or neurosensory detachment types of DME after three monthly injections of intravitreal bevacizumab in the first 6 months, which correspond to the results of our study. The explanation of this may be the histopathologic research showing that the accumulation of liquid begins with the intracytoplasmic swelling of the Müller cells ${ }^{(13)}$. Persistent edema is followed by liquefaction necrosis of the Müller cells and the adjacent neurons with formation of cystic areas in the retina ${ }^{(14)}$.

In eyes with severe cystoid edema there may be a confluence of the cystic areas which leads to 
retinoschistic appearance of the macula and leads to photoreceptors damage. These histopathology findings may explain the observed differences in visual acuity between the three types of nontractional DME. NSD occurs when the external limiting membrane (ELM)barrier breaks down at the fovea ${ }^{(15)}$. Loss of the ELM barrier often results in damage to foveal photoreceptors in the outer segment and lead to visual acuity (VA)impairment ${ }^{(16)}$. So, the mean VA of the NSD group may have been significantly worse as a result of damage to foveal photoreceptor cells due to foveal

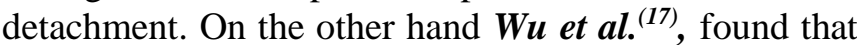
patients with cystoid change gained greater improvement in visual acuity and macular thickness and volume after intravitreal injection of bevacizumab (IVB). They studied 31 eyes ( 24 patients) with clinically significant macular edema that received IVB injections along with macular OCT data. The eyes were categorized into 4 groups by using OCT features: diffuse retinal thickening (DRT), cystoid macular edema (CME), serous retinal detachment (SRD), and vitreomacular interface abnormalities (VMIAs). Changes in retinal thickness, retinal volume, and visual acuity (VA) after IVB injection were compared on the basis of OCT patterns within three month of injections of IVB.

Haider et al. ${ }^{(6)}$ found that focal DME group was associated with most improvement of visual acuity following IVB. In this study, DME was classified into four categories; Focal, diffuse, focal cystoid and neurosensory detachment. Patients with focal DME had limited retinal thickening with cyst formation, and preservation of the macular contours and had better visual acuity. Koytak et al. $^{(18)}$ found that there was no statistically significant variation between focal, cystoid and neurosensory detachment groups regarding the change in BCVA. The aim of this study is to compare the therapeutic effect of a single intravitreal bevacizumab (IVB) injection in eyes with diabetic macular edema (DME) of different patterns determined by optical coherence tomography (OCT).

In many studies, the appearance of the photoreceptor layer, and the integrity of the inner segment-outer segment junction (IS/OS) line visualized by SD-OCT could be used to predict the functional outcomes $^{(\mathbf{1 9})}$. The visual acuity improvement was closely associated with IS/OS integrity in patients undergoing DME treatment ${ }^{(20)}$. In our study, we did not look at these parameters, and only evaluated the various patterns of OCT in DME

\section{CONCLUSION}

In this study, we found statistically significant improvement of BCVA and CMT in all groups of DME based on OCT pattern at final follow-up with greater reduction in CMT and superior BCVA improvement in DRT group.
Finally, OCT patterns in DME may predict the effects of IVR (ranibizumab) treatment, and patients with DRT are most likely to gain improvement of BCVA and reduction of CMT from this treatment at final follow-up.

\section{REFERENCES}

1.Williams R, Airey M, Baxter H, Forrester J, KennedyMartinT, Girach A (2004) : Epidemiology of diabetic retinopathy and macular edema: a systematic review. Eye, 18(10):963-983

2.Ciulla TA, Harris A, Latkany P, Piper HC, Arend O, Garzozi H, Martin B (2002):Ocular perfusion abnormalities in diabetes. Acta Ophthalmol Scand.,80 (5):468-477

3.Nguyen QD, Brown DM, Marcus DM, Boyer DS, Patel S et al.(2012): Ranibizumab for diabetic macular edema: results from 2 phase III randomized trials: RISE and RIDE. Ophthalmology, 119:789-801.

4- Telbizova-Radovanova K, Ilieva E, Petkova I (2014): Optical Coherence Tomography Patterns in Diabetic Macular Edema can Predict the Effectiveness of Intravitreal Bevacizumab Combined with Macular Photocoagulation. J Clin Exp Ophthalmol., 5:355.

5- Diabetic Retinopathy Clinical Research Network (2007): Reproducibility of macular thickness and volume using Zeiss optical coherence tomography in patients with diabetic macular edema. Ophthalmology, 114:1520-1525

6- Haider R, Ahmed A, Essam A(2014): Improvement of visual acuity based on optical coherence tomography patterns following intravitreal bevacizumab treatment in patients with diabetic macular edema. International Journal of Ophthalmology, 7:2.

7- Glover SJ, Burgess PI, Cohen DB, Harding SP, Hofland HW, Zijlstra EE(2012): Prevalence of diabetic retinopathy, cataract and visual impairment in patients with diabetes in sub-Saharan Africa. Br J Ophthalmol., 96 (2):156-161

8- Pelosini L, Hull CC, Boyce JF, McHugh D, Stanford MR, Marshall J (2011):

Optical coherence tomography may be used to predict visual acuity in patients with macular edema. Invest Ophthalmol Vis Sci.,52 (5):2741-2748

9- Kim BY, Smith SD and Kaiser PK (2006): Optical coherence tomographic patterns of diabetic macular edema. Am J Ophthalmol., 142(3):12-405.

10- Otani T, Kishi S, Maruyama Y (1999): Patterns of diabetic macular edema with optical coherence tomography. Am J Ophthalmol.,127:688-93.

11- Zhang X, Bao S, Hambly BD, Gillies MC (2009): Vascular endothelial growth factor-A: a multifunctional molecular player in diabetic retinopathy. Int J Biochem Cell Biol., 41: 2368-2371.

12-Kim M, Lee P, Kim Y, Yu SY, Kwak HW (2011): Effect of intravitreal bevacizumab based on optical coherence tomography patterns of diabetic macular edema. Ophthalmologica,226(3):138-144

13- Yanoff M, Fine BS, Brucker AJ, Eagle RC Jr (1984): Pathology of human cystoid macular edema. Surv Ophthalmol., $28: 505-511$.

14- Fine BS, Brucker AJ (1981): Macular edema and cystoid macular edema. Am J Ophthalmol.,92: 466-481.

15- Spaide RF, Lee JK, Klancnik JK Jr, Gross NE (2003): Optical coherence tomography of branch retinal vein occlusion. Retina, 23(3):343-7. 
16- Noma H, Funatsu H, Mimura T, Shimada K (2011): Visual function and serous retinal detachment in patients with branch retinal vein occlusion and macular edema: a case series. BMC Ophthalmol .,11:29.

17- Wu PC, Lai CH, Chen CL, Kuo CN (2012): Optical coherence tomographic patterns in diabetic macula edema can predict the effects of intravitreal bevacizumab injection as primary treatment. J Ocul Pharmacol Ther ,28(1):59-64

18- Koytak A, Altinisik M, Sogutlu Sari E, Artunay O, Umurhan Akkan JC, Tuncer K (2013). Effect of a single intravitreal bevacizumab injection on different optical coherence tomographic patterns of diabetic macular oedema. Eye (Lond) , 27(6):716-721

19- Suh MH, Seo JM, Park KH, Yu HG (2009): Associations between macular findings by optical coherence tomography and visual outcomes after epiretinal membrane removal. Am $J$ Ophthalmol.,147(3):473-480

20- Shin HJ, Lee SH, Chung H, Kim HC (2012): Association between photoreceptor integrity and visual outcome in diabetic macular edema. Graefes Arch Clin Exp Ophthalmo.,l250(1):61-70. 